what I had learned was well worth sharing with my colleagues. So I decided to write articles, which were published in Vital $^{1}$ and Hygienetown magazine, and also created an online course for Hygienetown, with PowerPoint slides and a recorded lecture. This was relatively easy for me to do in my home office, with my cats as an audience. These activities drew encouraging feedback from colleagues and mentors, who hinted at the possibility of me lecturing 'live' some time, so this spectre had returned to haunt me! I really wanted to help a wider circle of patients beyond my clinical practice, by giving lectures to my colleagues. However, I was ambivalent; while I knew that such an opportunity could be a great career move, I dreaded it. I feared the return of my old anxiety, and losing control of my tremulous voice and trembling hands again.

In September 2012, my dream (or nightmare) came true: Trisha O'Hehir, one of my mentors, and my professor at O'Hehir University (from where I recently graduated with a BSc in Oral Health Promotion) invited me to give a 90-minute presentation at the Townie (Dentaltown) Meeting in Las Vegas in April 2013! Initially, I demurred - I said I was not ready yet, but, with Trisha's encouragement, I accepted the invitation to speak. After all, it was an offer I couldn't refuse (in a good way).

I set to work: I had maintained current knowledge on my topic, so my presentation was up to date. I enrolled in a public speaking class for beginners and asked all of the speakers whom I admire for tips. They gave me lots of great advice and I was surprised to learn from every last one of these wellknown speakers that they all feel nervous before speaking - no matter how many years of experience they have - but it is viewed as a

'Who would have guessed? All of these knowledgeable accomplished speakers, who appeared supremely confident, actually felt nervous?' good thing: this nervous energy is channelled to enhance their presentation. Not feeling nervous could indicate a perilous complacency.

Who would have guessed? All of these knowledgeable accomplished speakers, who appeared supremely confident, actually felt nervous? This was a revelation to me. In fact, more profound than a revelation - an epiphany! Nervousness before speaking is not only normal; it is a positive thing!

I enjoyed my public speaking class immensely. Our class was a diverse group of great individuals: they included a housewife, who wanted to speak confidently with her daughter's teachers; a research scientist, who needed to give professional presentations; and a courageous lady, who was in remission from multiple sclerosis and had found her voice again, after being unable to speak for three years.

Our teacher, Paul, shared techniques to control nerves and project the voice for effective communication. We even learned about foods to avoid just before speaking: caffeinated drinks increase the 'jitters'; citrus, or milk products make you 'phlegmy', consequently needing to repeatedly clear your throat; and alcohol is a depressant - a definite no-no!

Instead of being my usual reserved self, I was determined to participate fully in this course. I forced myself to seize every opportunity to speak in front of the class. With perseverance, and the support of my teacher and classmates, my confidence and competence grew. When we completed the course, Paul suggested joining Toastmasters International as the next step. The club is made up of individuals who share a common goal: enhancing professional growth by becoming effective communicators.

I lived and breathed my presentation and my mission to develop my public speaking skills. I rehearsed almost every evening with my daughter Danielle, and did a 'dress rehearsal' for a group of friends. I looked online at floor plans of the venue, and asked the organisers questions about the equipment, and the capacity of the room. I planned to wear a smart outfit, which would boost my confidence, and Danielle made a lucky bracelet for me, with cute little dental charms, and she also joined me on the trip as my technical and moral support (and to go shopping in Vegas).

As the date of the Townie Meeting approached, I felt well prepared. I had my checklist and cue cards, and the PowerPoint presentation was on my laptop; it was also on a USB stick, and attached to my email!
'It seemed to me that

was the shyest and

most nervous person in the entire class, perhaps even the universe...'

In short, I had a back-up of my back-up! On the day of the lecture, I was so apprehensive that I could not eat beforehand. My heart fluttered while I was being introduced, but the techniques I had learned came together, and Tricia's reminder that 'the audience wants you to do well' was a great help. I took a few deep, slow breaths, and I was ON! After the initial butterflies, my enthusiasm for the topic, plus a few spontaneous flashes of my dry, British humour made my stage fright almost disappear. I controlled the nerves that remained, and managed to look and sound pretty confident. (It also helped that my colleagues in the US like my English accent.) When the presentation was completed, I received positive feedback from the audience, which was most gratifying.

After taking on this challenge, I feel like a different person. By moving beyond the constraints of my comfort zone, to that limitless place where the magic happens, my nightmare has now become my dream. Upon reviewing my debut with a critical eye, I knew there was room for improvement. Nevertheless, the positives certainly outweighed a few technical errors, and I felt good about how it turned out.

Now I am eager to go on to my next presentation, and in preparation for this, I am continuing to work on improving my speaking skills. No doubt my ancestors would be proud that I have finally emerged from my shell, to truly enjoy 'flapping my gums' for an audience.

I would like to share some tips that have helped me with Vital readers who might be contemplating public speaking:

1. Talk about what you know

2. Practise

3. Be prepared: arrive early and make sure you have your slides and notes and enough handouts for everyone

4. Mingle with your audience as they arrive, so you are not speaking to total strangers

5. Breathe: take slow, deep breaths before and even during your speech, to relax your vocal cords 


\section{'After the initial}

\section{butterflies, my enthusiasm}

\section{for the topic, plus a few}

spontaneous flashes of

my dry, British humour

made my stage fright

\section{almost disappear.'}

6. Pause to gather your thoughts

7. Accept some anxiety, and use it to focus

8. Hold a small object, like a pen, to channel nervous energy, and control the physical manifestations of nerves

9. Use an anchor, which is associated with a positive emotion (like my lucky dental bracelet)

10. Good posture prevents constriction of the diaphragm, and facilitates proper airflow through your vocal cords. This helps to control a quivering voice, and shows confidence; it also reduces your levels of stress hormones like cortisol, so that you actually feel more confident.

1. Douglas L M. Managing xerostomia. Vital spring 2009; 32-34.

Linda was also interviewed for Vital and wrote a two-part series on oral cancer screening:

- Bajaj A. 'I look forward to going to work each morning.' Vital 2009; 24-25.

- Douglas L M. Making oral cancer screening a routine part of your patient care, Part 1. Vital winter 2011; 44-47.

- Douglas L M. Making oral cancer screening a routine part of your patient care, Part 2. Vital spring 2012; 31-34.

\section{Useful resources}

www.evancarmichael.com/

Starting-A-Business/850/5-Powerful-Public-

Speaking-Techniques.html

http://mannerofspeaking.org

http://stingteachingtips.blogspot.ca/

www.toastmasters.org/

www.ohehiruniversity.com

www.towniemeeting.com/

www.ted.com/talks/amy_cuddy_your_

body_language_shapes_who_you_are.html

\section{VITAL READER PANEL}

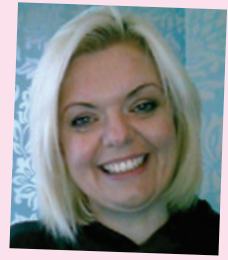

\section{Claire Deegan,}

\section{Practice Manager/Dental Nurse Tutor}

As a tutor I speak publicly every day. The size of groups I present to range from 5-40 delegates. To help increase my confidence levels in presenting verifiable CPD and compliance modules/workshops I undertook a further qualification - PTLLS - Preparing to Teach in the Lifelong Sector.

When I first started teaching I would rehearse my presentations and revise my topic you have to know your stuff! Be prepared for questions.

My top tips are: 1. Relax and be yourself - let your personality shine through! 2. Have confidence in your chosen subject knowledge 3. Use PowerPoint as a guide and not a script - avoid 'Death by PowerPoint'! 4. Make learning fun 5. Always ask for feedback reflect and evaluate your methods.

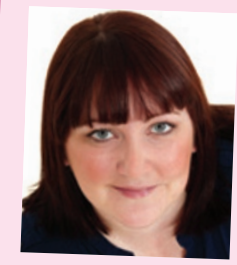

\section{Rachael England,} Dental Hygienist

I'm terrible at public speaking, I have given a few presentations, but even to a group of colleagues I get the shakes. A good friend of mine is having singing lessons to help with her confidence before speaking at a conference later this year. I've heard hypnotherapy works well and Definitely something for my bucket list!

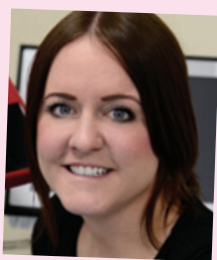

\section{Christine Horbury,}

\section{RDN dental clinical skills teacher}

My first ever public speaking experience was at university where I had to develop and present a lecture on my goals for the next three years. I felt extremely nervous due to lacking confidence and experience of presenting. I was also being graded for my presentation skills; the fear of failure and being judged by fellow students worried me. I feel the hardest lectures/presentations to give are the ones to colleagues, for example fellow dental nurses at CPD events. Having to be exposed in this way and the likelihood of being critiqued does heighten my nerves; however, I'm not as nervous lecturing to undergraduate dental students. First year dental students, for example, will not know a great deal about cross infection or communication skills for clinical practice.

My top tip is to know the environment you will be speaking in. If you can visit the place beforehand do so; I feel this has helped me but I am aware that this isn't always possible.

Individuals should not let the fear of failure when presenting worry them too much; having the guts to stand up there in the first place deserves a big pat on the back.

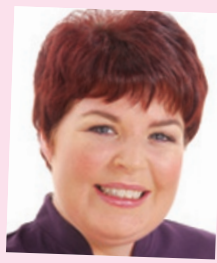

\section{Vanessa Radway, Dental Nurse}

I have done a number of well-being clinics and wedding shows in the past, giving a talk on teeth and explaining about the practice I work in, offering and chatting about tooth whitening, the plans we offer and answering general questions from the public.

At first I was bit nervous and it was daunting as I was going out of my comfort zone. I thought I wasn't confident at first but when I did it more I became confident as I actually enjoyed it and my nervousness completely disappeared. I was just myself and did what I did in work and just chatted to people, answering their questions. I have been a dental nurse for over 20 years so I could confidently answer the questions that were asked. When I gave a talk it helped to have prompts on a piece of paper.

I have just this week started a new job and one of my roles is to go into the local supermarket and go on their tannoy system to offer services and offers for our dental practice. This had made me nervous again as I feel that my voice will sound strange, I will make a mess of it or I may say something wrong or just laugh! I have had training on it today; it was nerve wracking but I feel if you say something scripted it will sound unfriendly and dull. I have realised you just have to be yourself, talk really slowly and don't
go too long. 